\title{
Labral Tears and Femoroacetabular Impingement: Clinical Features and Arthroscopic Management
}

\author{
Scott D. Martin ${ }^{1}$ and Jeffrey N. Katz*,1,2,3 \\ ${ }^{I}$ Department of Orthopedic Surgery; ${ }^{2}$ Orthopedic and Arthritis Center for Outcomes Research and ${ }^{3}$ Division of \\ Rheumatology, Immunology and Allergy, Brigham and Women's Hospital, Harvard Medical School, Boston, USA
}

\begin{abstract}
Context: Labral tears and femoroacetabular impingement (FAI) are increasingly recognized sources of hip pain and disability. FAI has two pathoanatomic phenotypes, Cam and Pincer impingement, and both of these lesions can cause labral tear and its associated symptoms, which can in turn lead to osteoarthritis. Hip arthroscopy is an increasingly popular technique with the potential to address these conditions.

Evidence Acquisition: The authors performed a PubMed search on labral tears, FAI, and hip arthroscopy, and further refined the search by pulling relevant citations from the retrieved articles.

Evidence Synthesis: Advances in hip arthroscopic techniques have made it possible to perform osteoplasty to treat the source of FAI and to perform labral repair. These procedures appear to be effective in relieving hip pain. However, randomized trials will be needed to perform a rigorous assessment of the efficacy of these procedures in pain relief. Longterm follow-up will be required to determine whether these surgical approaches reduce the risk of osteoarthritis.

Conclusions: Clinicians should be aware of labral tears and FAI as common causes of hip and groin pain and disability. Successfully addressing these conditions with hip arthroscopy requires advanced training and a detailed knowledge of the anatomy of the hip. Results have been favorable, but further study is needed to fully document the outcomes of arthroscopic interventions.
\end{abstract}

Keywords: Arthroscopy, femoroacetabular impingement, hip, labral tear, osteoarthritis.

\section{INTRODUCTION}

The introduction, development and gradual proliferation of hip arthroscopy has facilitated the management of several disorders that previously could only be managed surgically with an open procedure. This paper describes two related disorders in particular whose management has been altered dramatically by the advent of hip arthroscopy: labral tears and femoroacetabular impingement (FAI). We describe these lesions from the perspectives of pathoanatomy, clinical evaluation, and arthroscopic management. Because symptomatic labral tears arise frequently in the setting of FAI, we discuss the two disorders jointly.

Arthroscopy of the hip joint can be an extremely challenging but satisfying surgical procedure and has distinct differences from other more commonly scoped joints. Notably, the deep confines of the joint itself necessitate the use of traction for scoping the central compartment. Because of these anatomic confines and the attendant restriction of using rigid straight cameras, most viewing is usually accomplished with a 70-degree scope with a short focal length, which can make orientation difficult. As an additional challenge, most Orthopedic residency and fellowship programs have not

*Address correspondence to this author at the Department of Orthopedic Surgery, Brigham and Women's Hospital, 75 Francis Street, Boston, MA 02115, USA; Tel: 617-732-5338; Fax: 617-525-7900;

E-mail: jnkatz@partners.org provided formal training in hip arthroscopy for the removal of loose bodies and joint debridement due to the technique's limited use in recent years [1].

As a result of these unique challenges, relatively little attention has been paid to arthroscopy of the hip over the years compared to other joints of the body. This is now changing, however, due to a number of recent developments: improved diagnostic tools and physical examinations have increased the detection of intra-articular hip pathology [1-3], refined surgical techniques like femoroacaetabular osteoplasty and labral repair have improved our ability to correct it, and high-profile cases of professional athletes seeking hip arthroscopy have substantially increased public awareness of the technique. Due in no small part to these factors, there has been a surge of interest in hip arthroscopy and the conditions it can address.

\section{LABRAL TEARS}

\section{Pathoanatomy}

Labral tears are one of the most frequent indications for performing hip arthroscopy, with most tears occurring in the anterosuperior location [4]. In 1998, Konrath reported that the labrum had little significance in load transmission of the hip [5], and three years later, McCarthy reported on the role of labral lesions in the development of early degenerative hip disease [6].

In contradistinction, more recent studies on hip labrum morphology and function have emphasized the importance 


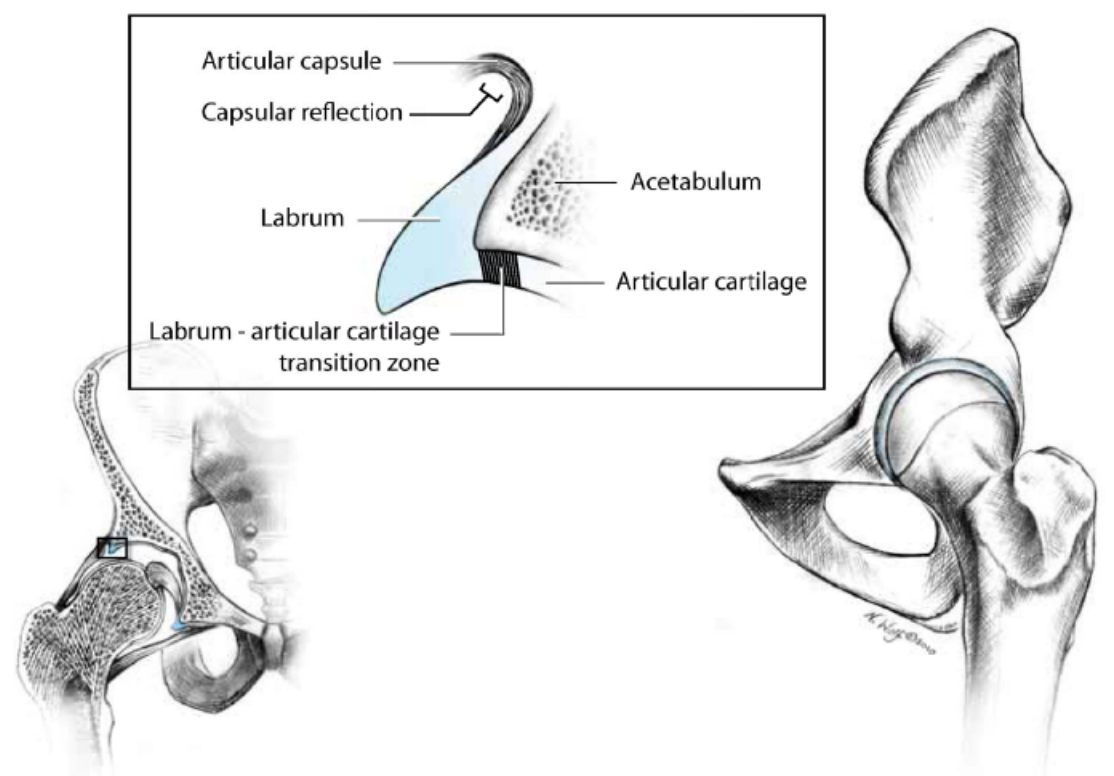

Fig. (1). Anatomic drawing of hip depicting seamless transition of articular cartilage to the labrum through a transitional zone at the periphery of the joint.

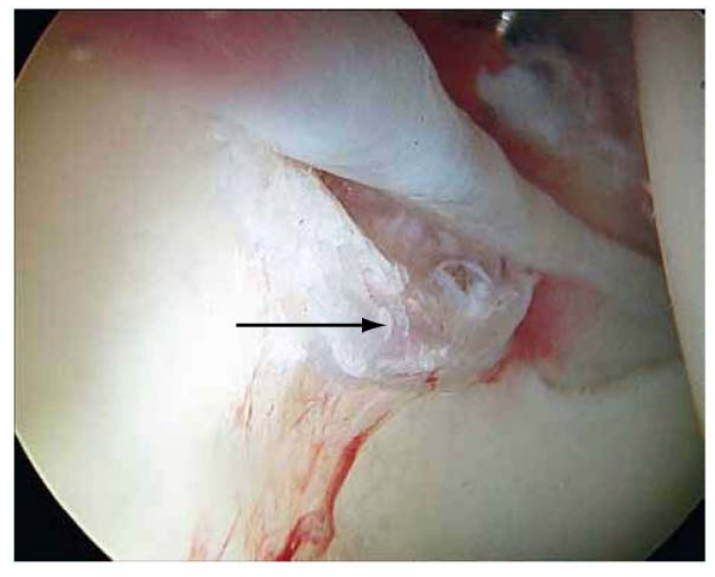

a

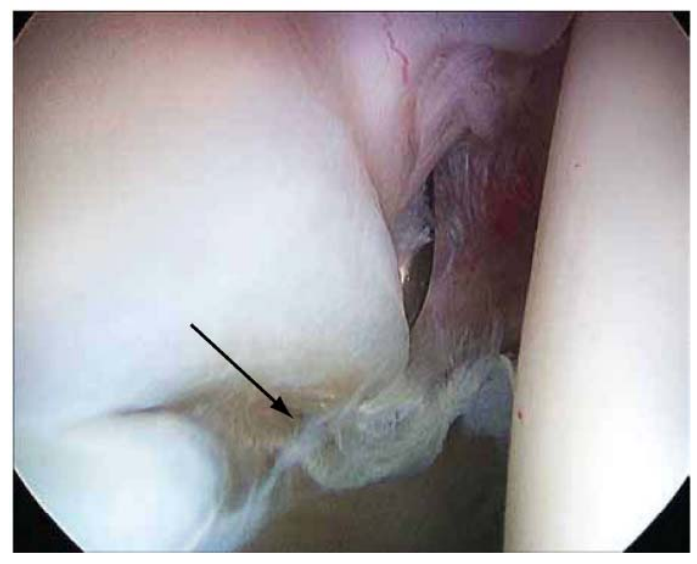

b
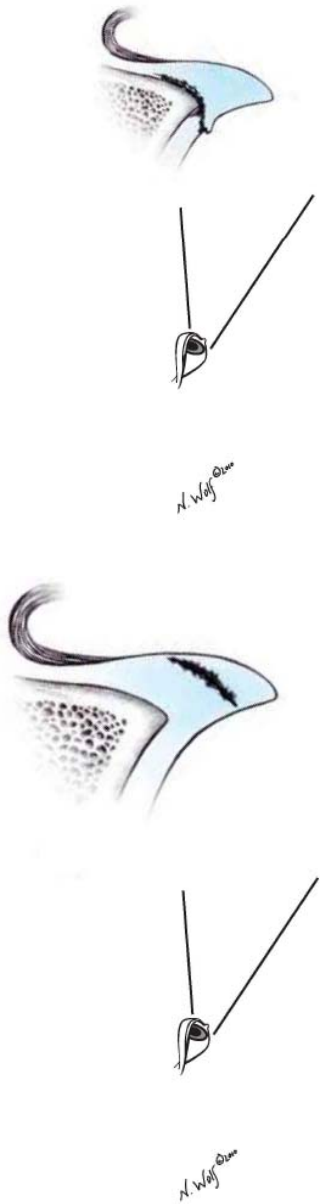

Fig. (2). a. Type I labral tear: Detachment of the fibrocartilaginous labrum from the articular hyaline cartilage at the transitional zone. The tear is indicated with an arrow.

b. Type II labral tear: Cleavage plane is through the substance of the labrum. The tear is indicated with an arrow. 
of the labrum in maintaining joint stability $[7,8]$. The sealing effect of the labrum on the hip not only enhances joint stability, but is also thought to more uniformly distribute compressive loads, thereby reducing peak cartilage stresses during weight-bearing [8]. In the normal hip joint, there is a seamless transition of articular cartilage to the labrum through a transitional zone at the periphery of the joint (Fig. 1).

Seldes has described two main types of tears in the adult acetabular labrum: Type I tears involve detachment of the fibrocartilaginous labrum from the articular hyaline cartilage at the transitional zone (Fig. 2a), while Type II tears consist of cleavage tears through the substance of the labrum (Fig. 2b) [9]. Both types of tears have been noted to be associated with an increased vascular response within the area of the tear, indicating a potential for healing (Fig. 3). The results from these studies and the promising early published results of arthroscopic labral repair in properly selected patients suggest that labral repair should be considered for patients who meet specific criteria, to be discussed below [10].

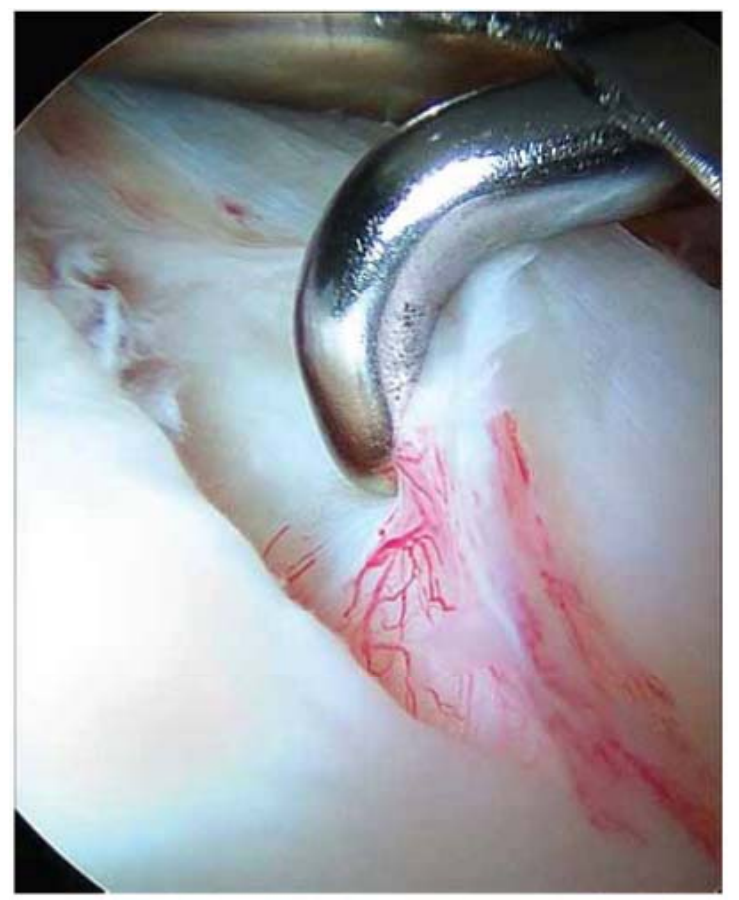

Fig. (3). Increased vascular response within the area of labral tears indicates a potential for healing.

\section{FEMOROACETABULAR IMPINGEMENT (FAI)}

\section{Pathoanatomy}

FAI is caused by an impingement of the femoral headneck junction against the acetabular rim. In 2003, Ganz et al., described FAI as a possible cause of early osteoarthritis [11], and several subsequent studies have supported this causal link [12-17]. These studies suggest that subtle and often unrecognized developmental abnormalities of the hip with alteration and malrotation of the femur and/or acetabulum may be responsible for secondary osteoarthritis of the hip [17]. There are two mechanisms of FAI: Cam impingement, which is caused by a non-spherical head, and Pincer impingement, which is the result of excessive acetabular coverage (Fig. 4) [18-22].
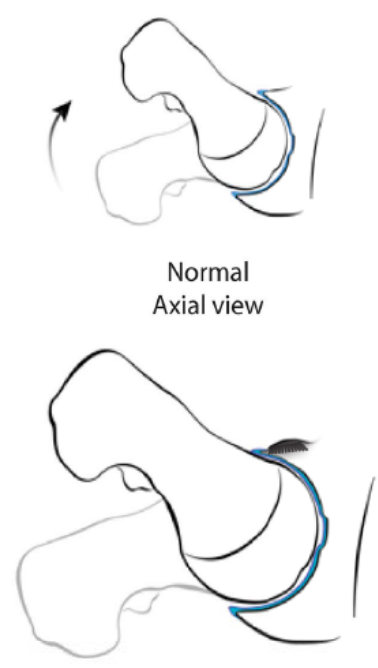

Pincer impingement

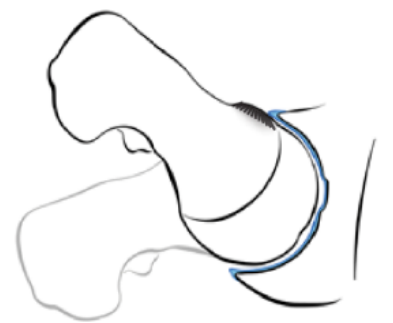

Cam impingement

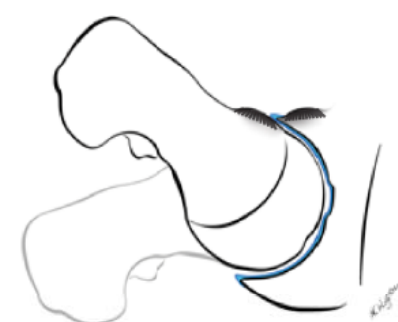

Combined cam \& pincer impingement
Fig. (4). There are two types of femoroacetabular impingement. Cam impingement is caused by a non-spherical head, while Pincer impingement is caused by excessive acetabular coverage. It is possible to have both types of impingement on a single joint.

Cam impingement most commonly occurs in young athletic men. The impingement of the Cam lesion occurs with flexion and internal rotation of the hip: the nonspherical deformity of the femoral head lifts up the labrum upon entering the joint, which can shear the articular cartilage from the subchondral bone and labrum (Fig. 5). The acetabular labrum undergoes partial undersurface tearing with fraying as it is pushed superiorly by the impingement lesion. An acetabular cartilage "wave sign" is often noted, demarcating delamination and shearing of the anterosuperior articular cartilage from the subchondral plate as the articular cartilage is compressed and pushed centrally (Fig. 6) $[11,17]$.

In Cam impingement, the femoral head is considered aspherical if, on the cross table lateral, it protrudes outside of a best-fit circle and extends anteriorly in a convex shape onto the base of the femur $[13,18,19]$. If the alpha angle as described here is greater than 55 degrees it is considered abnormal and a possible source of FAI (Fig. 7). Cam lesions cause a decrease in the femoral head-neck offset resulting in a decreased clearance between the labrum and the femoral head neck junction. Over time, reduced clearance leads to tearing and pushing of the labrum away from the joint with delamination and separation of the articular cartilage at the chondrolabral junction.

Possible causes of the Cam lesion include slipped capital femoral epiphysis, previous trauma of the head-neck region of the hip, and epiphyseal overgrowth [20-23]. The Cam lesion is thought to be the cause of impingement rather than the result of repetitive trauma to the head-neck region. In younger patients without established osteoarthritis, FAI including Cam and Pincer lesions are not considered a disease entity in and of themselves but are part of a pathomechanical process that may lead to osteoarthritis. In the older patient with established osteoarthritis with little or no joint space remaining, Cam lesions along the femoral head-neck junction are considered osteophytes. 


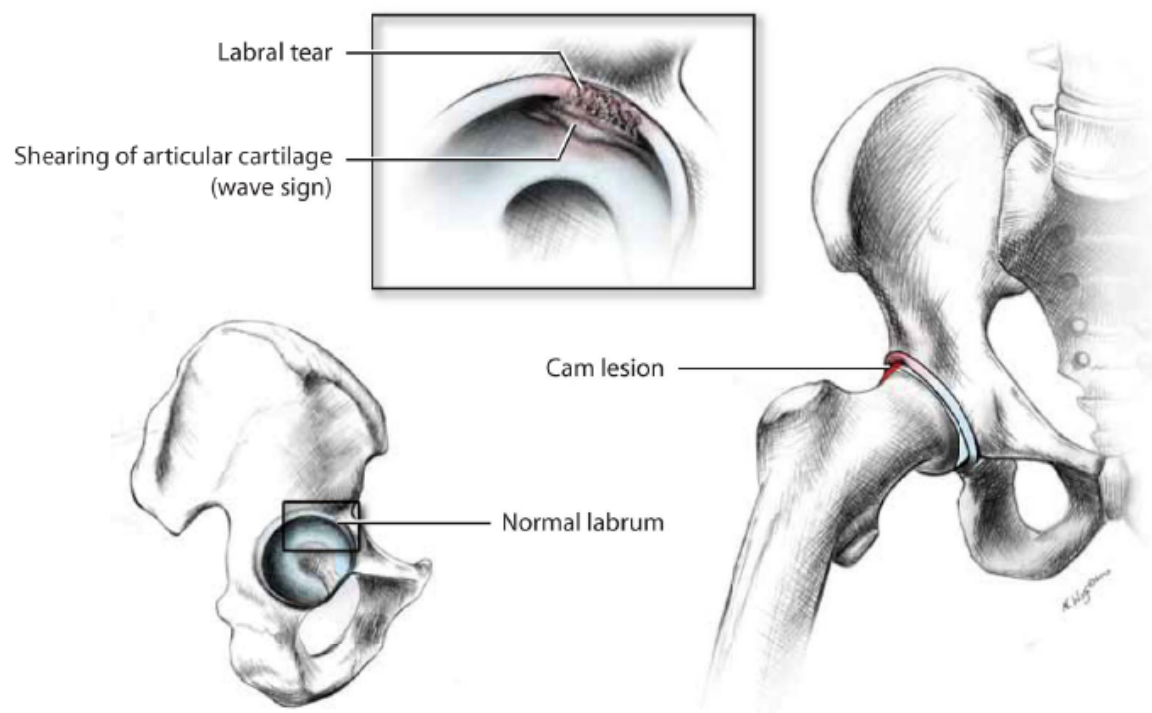

Fig. (5). In Cam impingement, the nonspherical deformity of the femoral head lifts up and tears the labrum upon entering the joint and shears the articular cartilage from the subchondral bone and labrum.

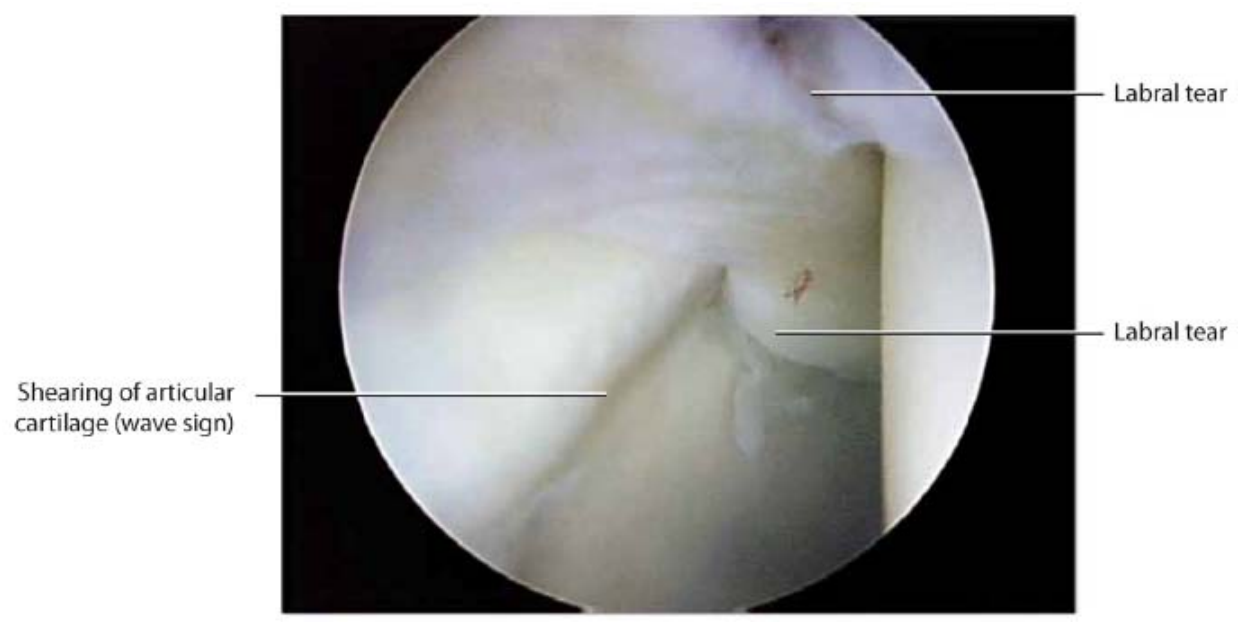

Fig. (6). Arthroscopic view of right hip of impinged hip. The articular cartilage is compressed and pushed inward. Delamination and shearing of the anterosuperior articular cartilage from the underlying bone can result in an acetabular cartilage "wave sign."

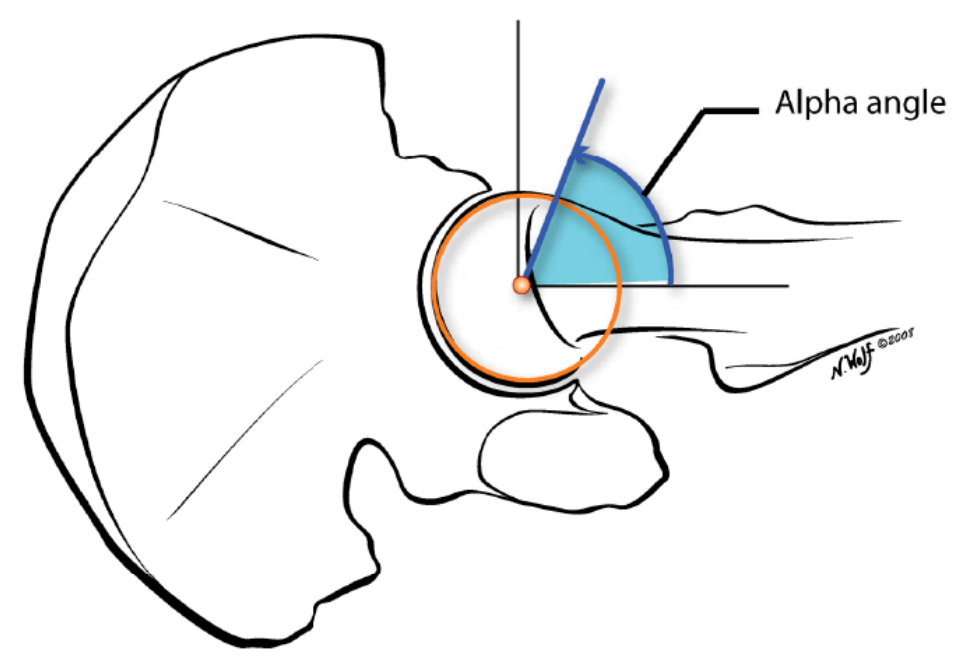

Fig. (7). If the alpha angle of the femoral head is greater than 55 degrees, it is considered abnormal and a possible source of Cam-type femoroacetabular impingement. Any bone outside of a best fit circle can lead to femoroacetabular impingement. 
Pincer lesions result from an overcoverage of the acetabulum on the femoral head, resulting in "pinching" of the anterior superior labrum with resultant tear. Pincer leasions result from either global retroversion of the acetabulum or, more commonly, cranial retroversion of the acetabulum. This results in impingment of the femoral neck against the labrum and acetabular rim with resultant tearing of the labrum but little damage to the articular cartilage.

More commonly, patients with FAI have a combination of Cam and Pincer lesions which must both be addressed at surgery for labral repair to be successful.

\section{CLINICAL FEATURES OF LABRAL TEARS AND FAI}

Patients who present with labral tears of the hip almost always have an abnormal boney hip morphology that limits hip motion (especially internal and external hip rotation) and causes repetitive impact of the femoral neck and acetabular rim, resulting in a labral tear [24]. Thus, in most patients, the clinical presentation of labral tear is inextricably linked with FAI.

Patients with labral tears oftentimes complain of mechanical symptoms of locking and/or catching, which are exacerbated by squatting, pivoting and positional pain that fails to improve with rest. With sudden pivoting and changeof-direction maneuvers, patients may experience sharp pain localized to the groin with a feeling of giving way. Some labral tears may be relatively stable, only producing symptoms occasionally with quick pivoting, such as a twist [25, 26]. The presence of mechanical symptoms generally suggests a better response to surgery [3], and the pain is often relieved quickly by adjusting the position of the hip.

Patients with FAI usually present complaining with a history of pain localized to the groin and lateral thigh. This symptom complex is often described by the "C-sign," where the patient will place the thumb over the posterior aspect of the trochanter with the fingers gripping into the groin. $\mathrm{Pa}$ tients will oftentimes complain of pain when sitting in deep chairs, a position that causes impingement of the head-neck region of the femur with the acetabulum and labrum.

When labral tears are associated with FAI, prolonged sitting may be uncomfortable and torsional twisting activities may exacerbate pain. In addition, rising from a deep chair may cause painful catching, a limitation associated with difficulty getting into and out of cars. Hip rotation is usually limited, impeding any foot care activities that require crossing the legs.

With both FAI and labral tears, patients complain of pain with hip flexion, adduction and internal rotation (FLAIR test), and with flexion, abduction, and external rotation (FABER test). The FABER test is also referred to as the "figure of four" test, which is the position for putting on shoes and socks.

Cam and Pincer lesions tend to have somewhat distinct clinical presentations. Cam impingement lesions occur more commonly in young males, whereas Pincer lesions are more commonly found in female athletes and middle-aged women. Patients with Cam lesions will oftentimes have significant loss of motion and degenerative changes, with tearing of the chondrolabral junction. These patients complain of aching and pain, especially with getting up out of a deep chair or trying to cross their legs. Patients with Pincer lesions may have very little loss of motion and usually complain of mechanical symptoms like locking or catching. They usually have very little articular cartilage damage at presentation and usually present because of an unstable labral tear [27].

\section{Radiographic Evaluation}

Proper radiographic FAI evaluation is done with an AP radiograph $\mathrm{x}$-ray beam centered on the pubis symphysis with

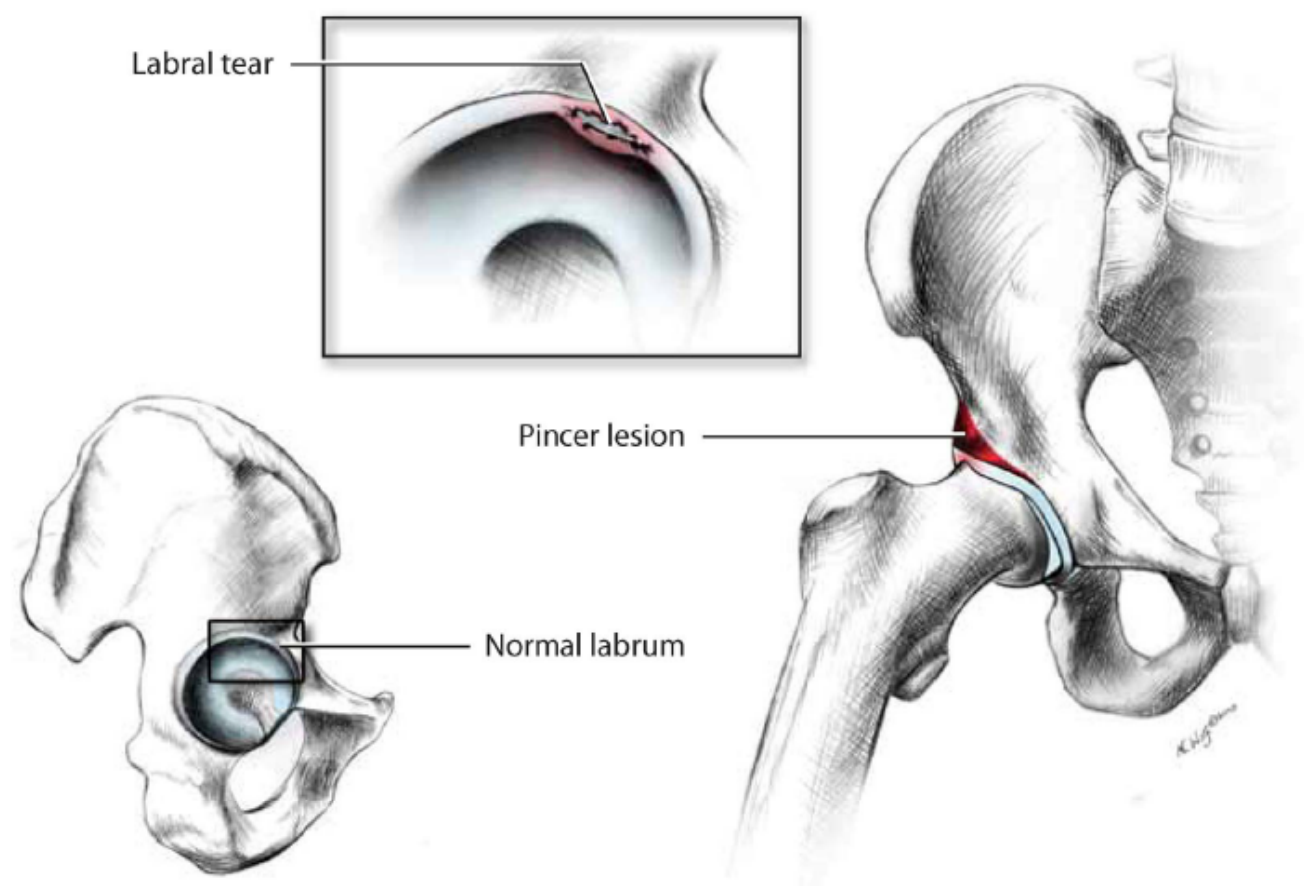

Fig. (8). In Pincer impingement, excessive acetabular coverage can trap or "pinch" the labrum, resulting in a labral tear. 
the coccyx within two centimeters of the symphysis. A cross table lateral is performed to adequately evaluate for a Cam and/or Pincer impingement lesion, both of which produce an abnormal linear contact between the normal femoral neck and the overhanging acetabular rim with the mechanism described as Pincer impingement, as the labrum becomes trapped or pinched in between (Fig. 8).

Radiographically the Cam lesion is visible as a bump at the superior lateral portion of the femoral head-neck junction on the AP radiograph and on the anterior head-neck junction on the lateral radiograph. Pincer lesion will appear as a cross-over sign on the AP radiograph.

In the radiographic evaluation of Pincer impingement, a crossover sign may be noted on AP radiographs noting cranial retroversion of the acetabulum caused by an anterolateral overhang of the rim [1]. In cases of global retroversion the acetabulum, the posterior wall will be noted to be medial to the center of the femoral head and is referred to as the "posterior wall sign". Pincer impingement may also be caused by global retroversion of the acetabulum or by coxa profunda, where there is increased depth of the acetabulum (Fig. 9) [23].

In most cases of symptomatic FAI with possible concomitant labral tear, an MRI arthrogram is obtained to verify the labral tear and to evaluate any chondral damage. In cases of hip dysplasia or cases of global retroversion of the acetabulum, CT arthrograms with 3 -d reconstruction can be extremely helpful in surgical planning.

\section{NONOPERATIVE MANAGEMENT OF FAI AND LABRAL TEARS}

There is general agreement that patients with labral tear and FAI should initially be treated conservatively with modification of activites, non-steroidal antiflammatory drugs (NSAIDs), and intra-articular steroid injection, although the benefits of these interventions have not been established.
Patients are advised to modify activities, avoiding deep squatting and high torsional twisting activities such as soccer, hockey, basketball, and racquet sports in favor of nonimpact loading exercises like swimming and using a bicycle or elliptical trainer. Surgical indications include failure of conservative treatment, less than two millimeters of joint space narrowing, and clinical and radiographic evidence of labral tear and FAI. Physical therapy is used to strengthen the muscles about the hip, normalize associated muscular imbalances, and to improve range of motion [25, 28, 29]. Currently, there are no dedicated prospective studies documenting conservative treatment of FAI, with most studies being controlled case studies of patients that have failed conservative treatment and undergone surgery.

\section{HIP ARTHROSCOPY}

\section{General Considerations in Hip Arthroscopy}

Before we discuss specific aspects of the arthroscopic management of particular hip disorders, we will first provide a more general description of the technical aspects of hip arthroscopy. The structure of the hip joint presents salient differences from other joints approached arthroscopically, such as the knee and shoulder [10]. Notably, the deep confines of the joint itself necessitate the use of traction for gaining access to the central compartment. In addition, the joint is surrounded by a thick layer of soft tissue and muscle, which greatly increases the working distance from the surface of the skin to the tip of instruments, making triangulation more difficult (Fig. 10). The capsule of the hip joint is also thicker and less resilient than that of other joints, which reduces instrument maneuverability. Often, a capsulotomy is necessary to allow increased freedom of movement and to avoid damage to instruments. Because of these anatomic confines and the concomitant restriction of using rigid straight cameras, most viewing is accomplished with a 70degree arthroscope with a short focal length, which can make orientation difficult.

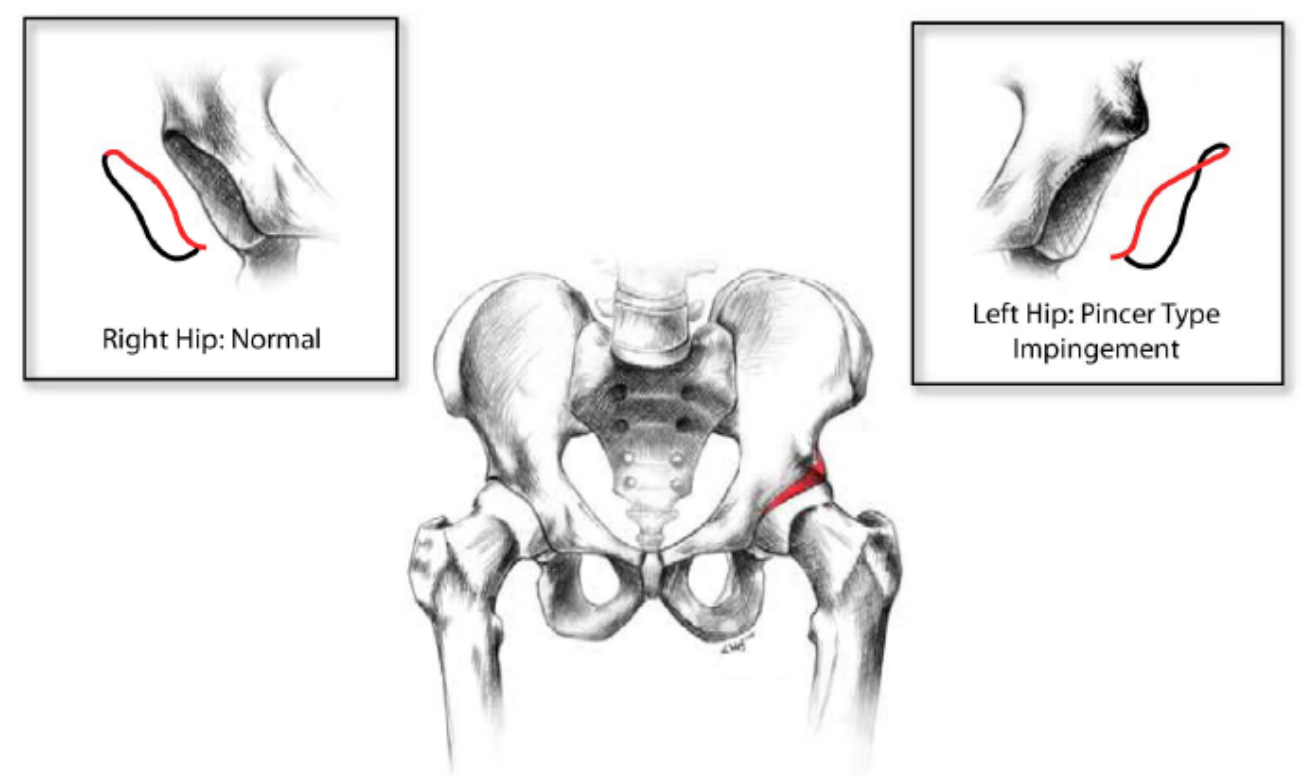

Fig. (9). Pincer impingement may also be caused by retroversion of the acetabulum or by coxa profunda, where there is increased depth of the acetabulum. 


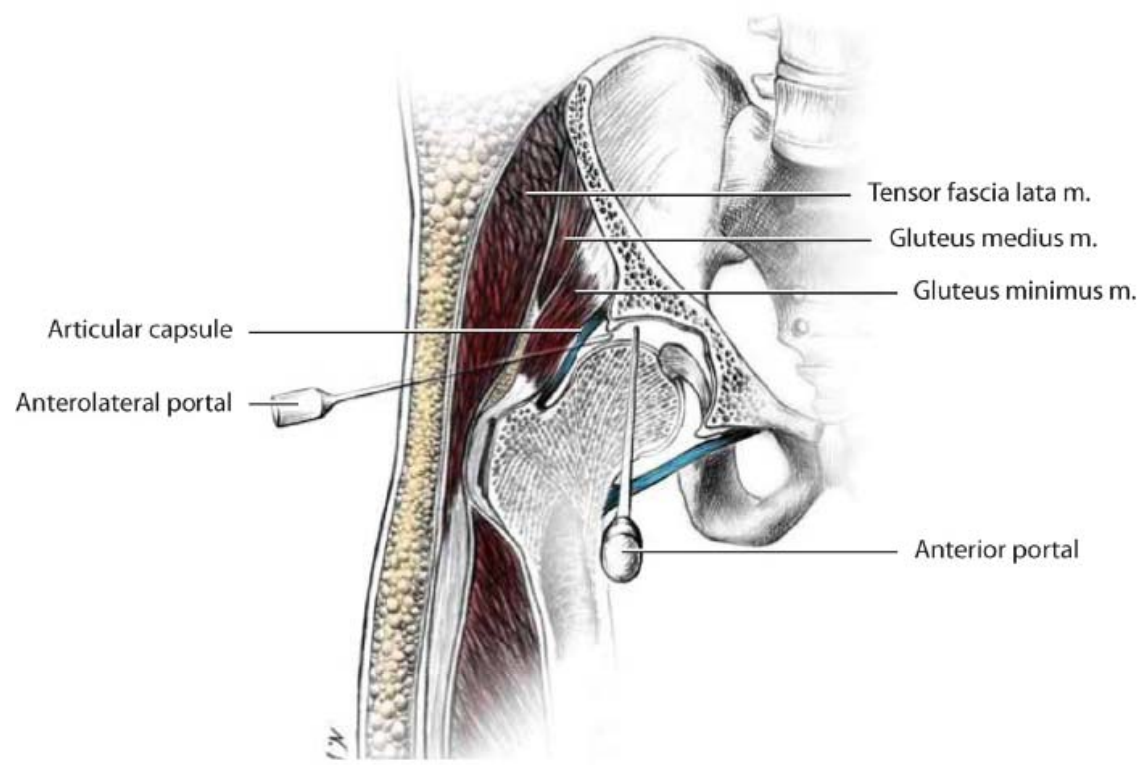

Fig. (10). Hip arthroscopy is challenging because the hip joint is surrounded by a thick layer of soft tissue and muscle. This increases the working distance from the surface of the skin to the tip of the instrument, making triangulation more difficult.

The most common surgical positioning for hip arthroscopy is supine, however the procedure can also be performed in the lateral position and is contingent upon surgeon preference. Patients are positioned on a hip distraction table that allows variable amounts of traction to be applied to the operative leg to distract the hip an average of one centimeter. A slight amount of counter-traction is also applied to the contralateral leg to anchor the pelvis level and keep it from moving during hip distraction. The patient is placed against a well-padded perineal post that is lateralized to the surgical side. The resultant vector is in line with the femoral neck and facilitates distraction of the hip (Fig. 11). Traction times are kept below two hours to prevent nerve injury, the most common of which is pudendal neuropraxia, which can cause numbness to the scrotum or labia (Fig. 12) [2].

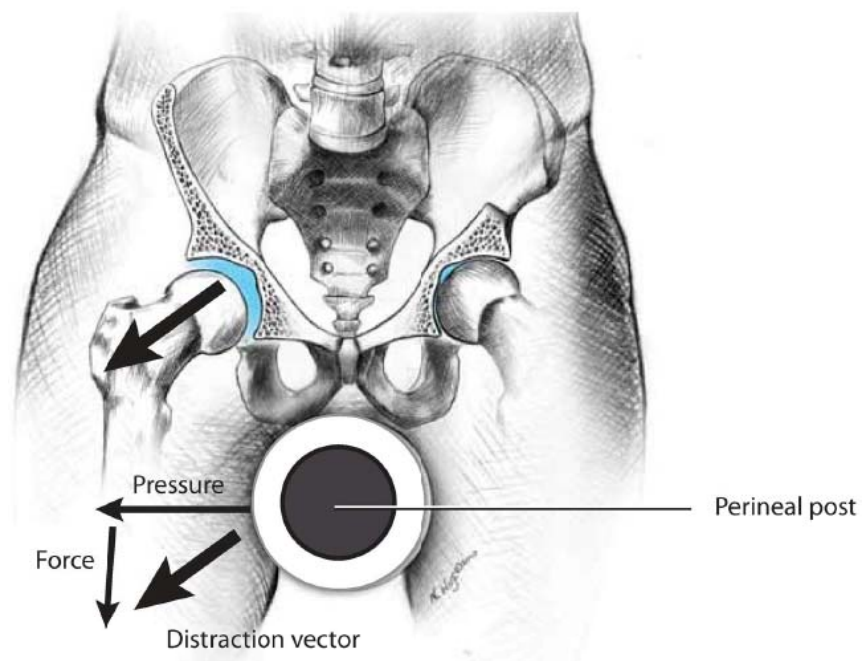

Fig. (11). In hip arthroscopy, the patient is placed against a wellpadded perineal post that is lateralized to the surgical side. The resultant vector is in line with the femoral neck and facilitates distraction of the hip.
The contralateral leg is abducted to allow for passage of the fluoroscopic C-arm. Attention to portal placement during hip arthroscopy is critical to avoid damaging surrounding neurovascular structures and to facilitate access to all parts of the central and peripheral compartments (Fig. 13).

At the start of the procedure, traction is applied to obtain approximately one centimeter of joint clearance. The safe zone for establishing portals lies lateral to the sagittal plane distal to the ASIS. Portal placement medial to this plane can result in catastrophic neurovascular injury and must be avoided (Fig. 14).

There are two compartments of the hip that are contained by the joint capsule. The central hip compartment provides the articulation between the femoral head and acetabulum and requires hip distraction for access. The peripheral compartment of the hip does not require traction to access. It lies along the femoral neck and extends from the hip joint to the capsular reflection on the intertrochanteric junction to the medial and lateral gutters and the inferior recess of the joint (Fig. 15). The labrocapsular junction, acetabular rim and femoral neck can be accessed through the peripheral compartment, as well as through the psoas tendon when tendon recession is required [3].

Outside of the hip joint, the superficial and deep paratrochanteric spaces are potential spaces that can be insufflated with fluid and accessed endoscopically to treat disorders of the iliotibial band, trochanteric bursa, iliopsoas tendon, and gluteal tendon reattachments.

\section{Surgical Indications and Operative Management of Labral Tears and FAI}

The ideal surgical candidate is a patient with welldocumented symptomatic labral tear and FAI whose symptoms go back at least one month and who has failed respond to conservative therapy. Patients should have mechanical symptoms, including activity-related hip pain localized around the groin, worse with flexion and internal rotation. 


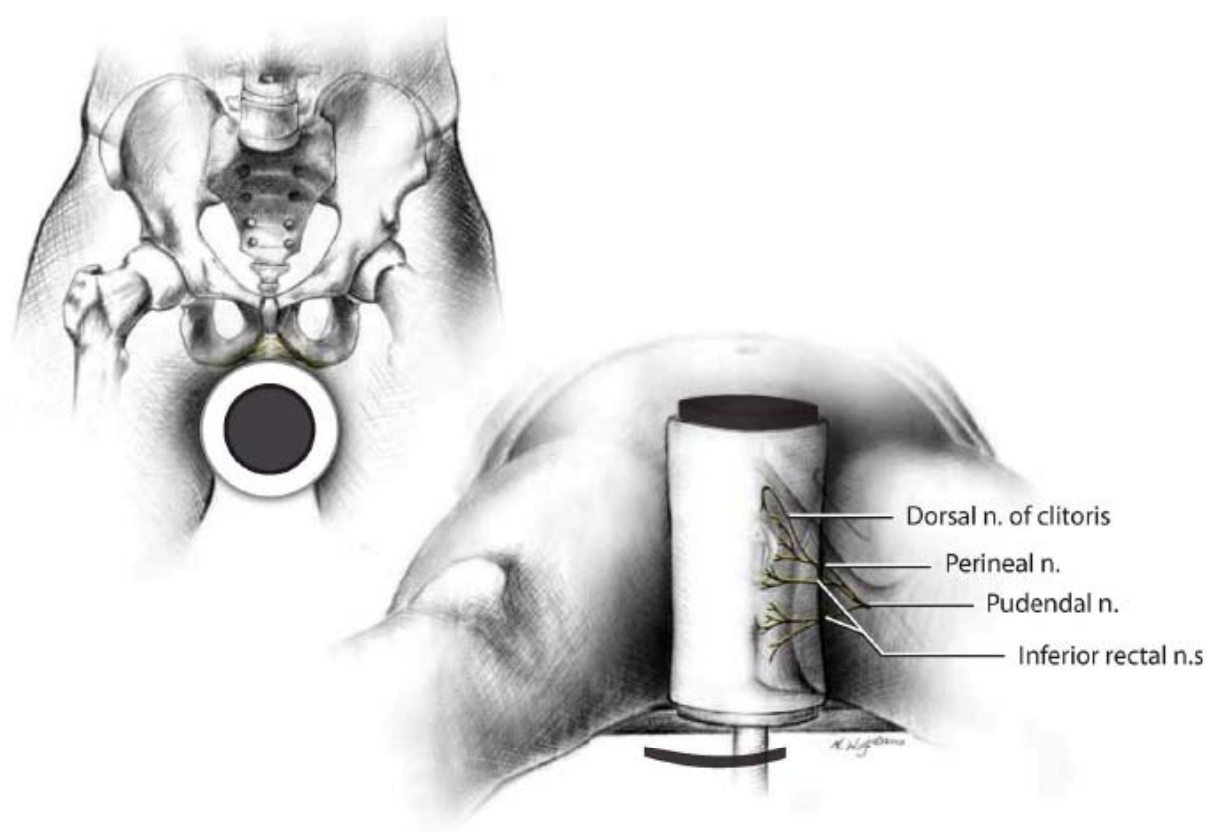

Fig. (12). Traction times for arthroscopic surgery are kept below two hours to prevent nerve injury, the most common of which is pudendal neuropraxia, which can cause numbness to the scrotum or labia.

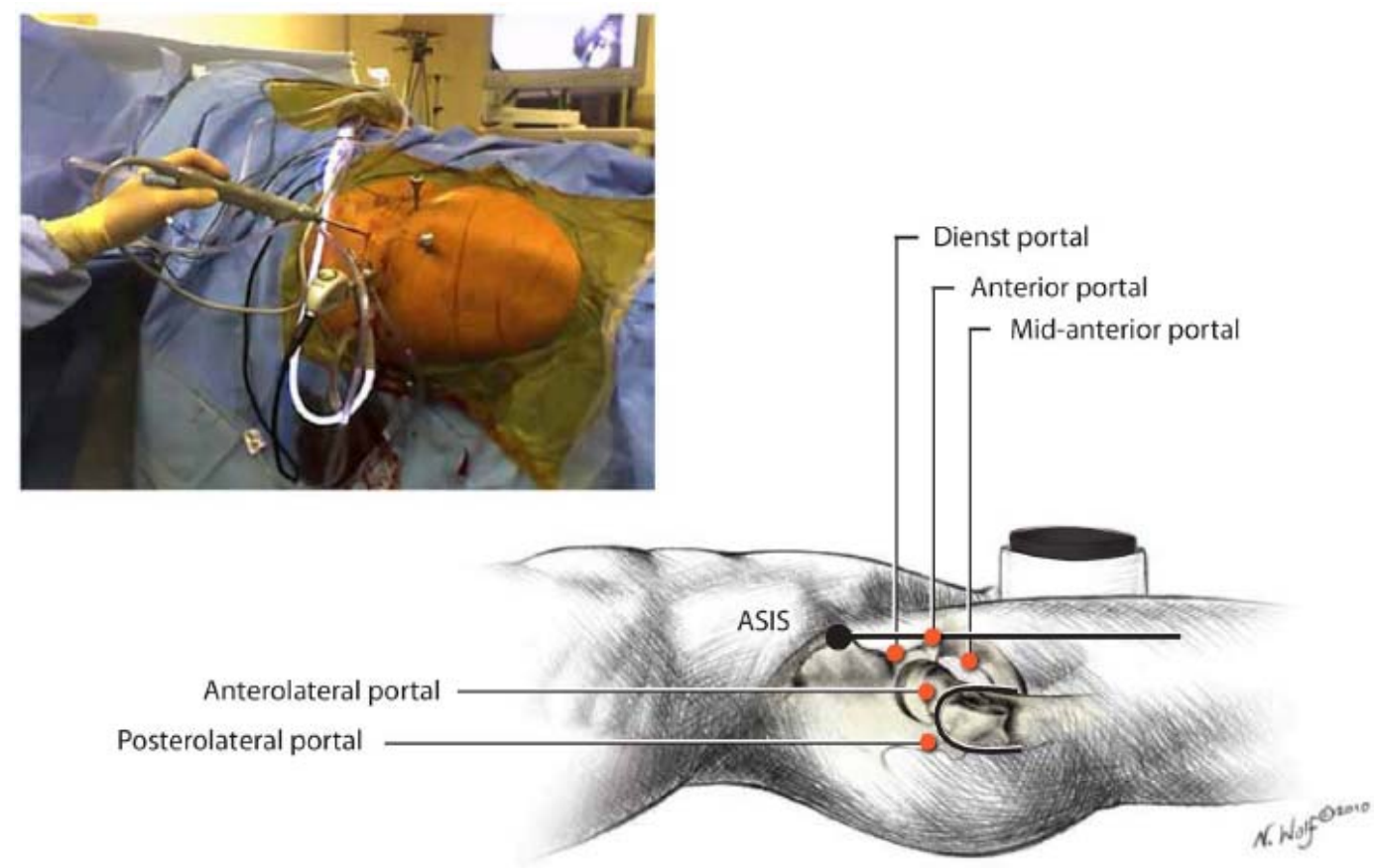

Fig. (13). Attention to portal placement during hip arthroscopy is critical to avoid damaging surrounding neurovascular structures and to facilitate access to all parts of the central and peripheral compartments.

The physical exam should reveal limited hip flexion and internal rotation, particularly in the setting of Cam lesions, with positive impingement tests. Patients should have a radiographically well-defined Cam or Pincer deformity with little or no secondary osteoarthritis and a lack of global retroversion or severe dysplasia. Patients should have an identifiable labral tear with a correctable impingement deformity defined by radiology and MRI with absence of grade IV chondral defects and less than two millimeters of joint space narrowing. Patients meeting these criteria will generally be less than 55 years old, as older patients will usually have a greater extent of hip osteoarthritis [28].

The goals of surgery are to eliminate the impingement lesion while preserving the joint and protecting the function of the labrum. The appropriate timing for surgical intervention in treating FAI continues to evolve. The only caveat in delaying surgical intervention is that disease progression may continue to the point where joint preservation is no longer possible, as joint space narrowing of greater than two millimeters is associated with inferior results [30, 31]. 


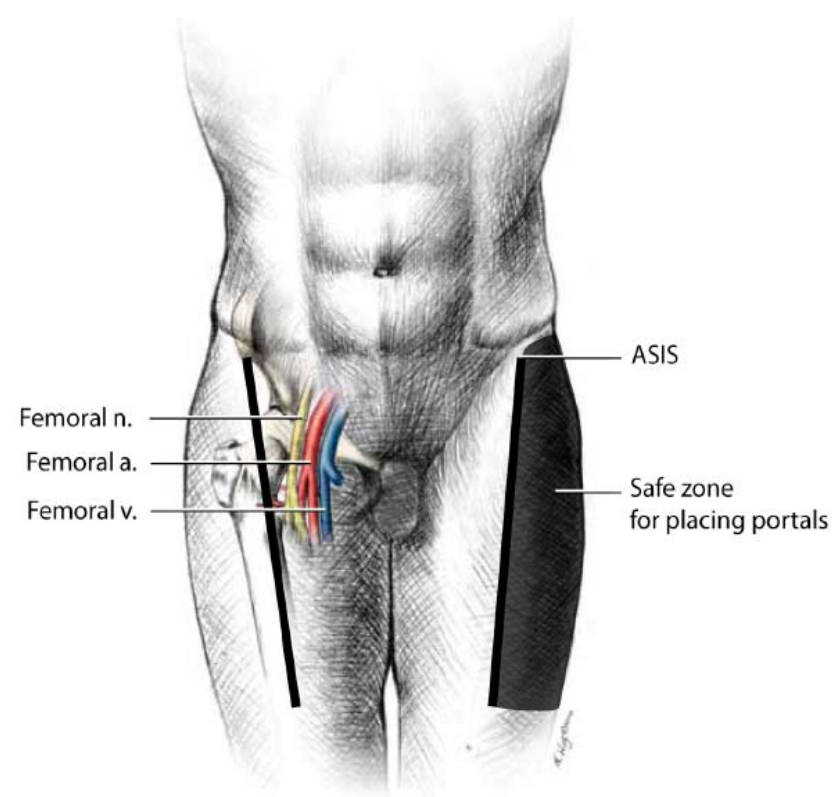

Fig. (14). The safe zone for establishing portals lies lateral to the mid-sagittal plane distal to the ASIS. Portal placement medial to this plane can result in catastrophic neurovascular injury.

Open surgery for the treatment of FAI and labral tears is a more invasive surgical procedure that requires admission with resultant increased costs of hospitalization. The open surgical exposure requires dislocation of the femoral head, which can lead to injury of the blood supply to the femoral head with resultant avascular necrosis which has never been reported in the literature with arthroscopic treatment. Open treatment can also lead to greater stiffness from surgical scarring and an increased risk of heterotopic bone deposition compared with arthroscopic treatment. Arthroscopic treatment is done as a day surgery, is minimally invasive with small incisions, and causes minimal trauma to the soft tis- sues. Arthroscopic treatment facilitates rehabilitation with quicker return of muscles strength and less pain from soft tissue damage.

\section{ARTHROSCOPY FOR LABRAL TEAR}

\section{Arthroscopic Management of Labral Tear}

Treatment of labral tears of the hip is decided based on patient age, symptoms, failure of conservative therapy, and minimal osteoarthritis with less than two millimeters of joint space narrowing. The final decision on possible labral repair versus debridement is made at the time of surgery and depends on the condition of the labrum, which must have good tissue viability that will support sutures without pulling through.

Arthroscopic labral repair is usually accomplished utilizing the anterolateral, midanterior, and anterior portals [7, 32]. Suture anchors are placed using accessory portals. Anchor placement must be into the acetabular rim, taking care to avoid violating the articular surface of the acetabulum. Single- or double-loaded anchors may be used with knots tied on the capsular surface away from the joint surface (Fig. 16).

Successful labral repair requires proper patient selection, adequate tissue, and a secure repair. Preserving as much viable hip labrum as possible appears to be critical for joint preservation and the maintenance of normal hip function. Loss of labral tissue has been associated with the development of hip arthritis over time [6, 8].

\section{Results of Arthroscopic Treatment of Labral Tear}

Although there have been many publications on labral debridement, reports of the results of labral repair have been sporadic. Espinosa et al., found patients undergoing open debridement for FAI with refixation of labral repairs did better than those with labral resection [33]. In a series of

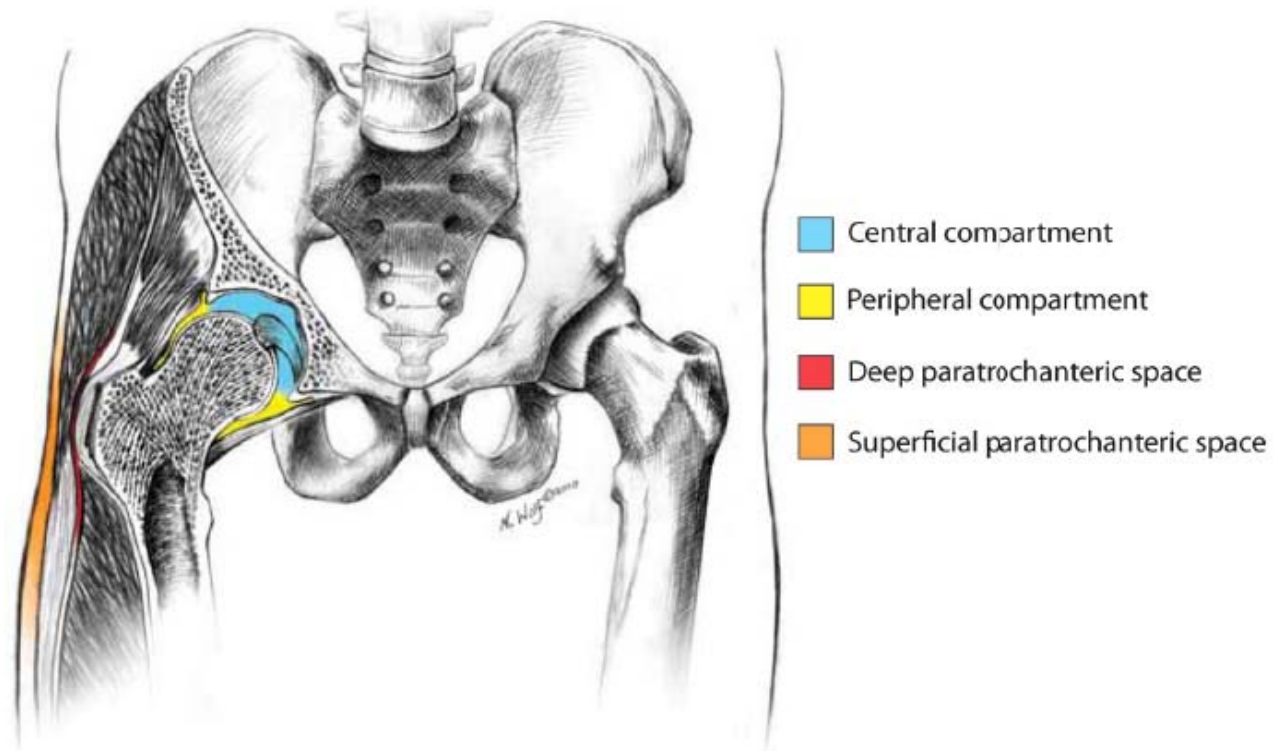

Fig. (15). There are two compartments of the hip that are contained by the joint capsule. The central hip compartment provides the articulation between the femoral head and acetabulum and requires hip distraction for access. The labrocapsular junction, acetabular rim and femoral neck can be accessed through the peripheral compartment without traction. 

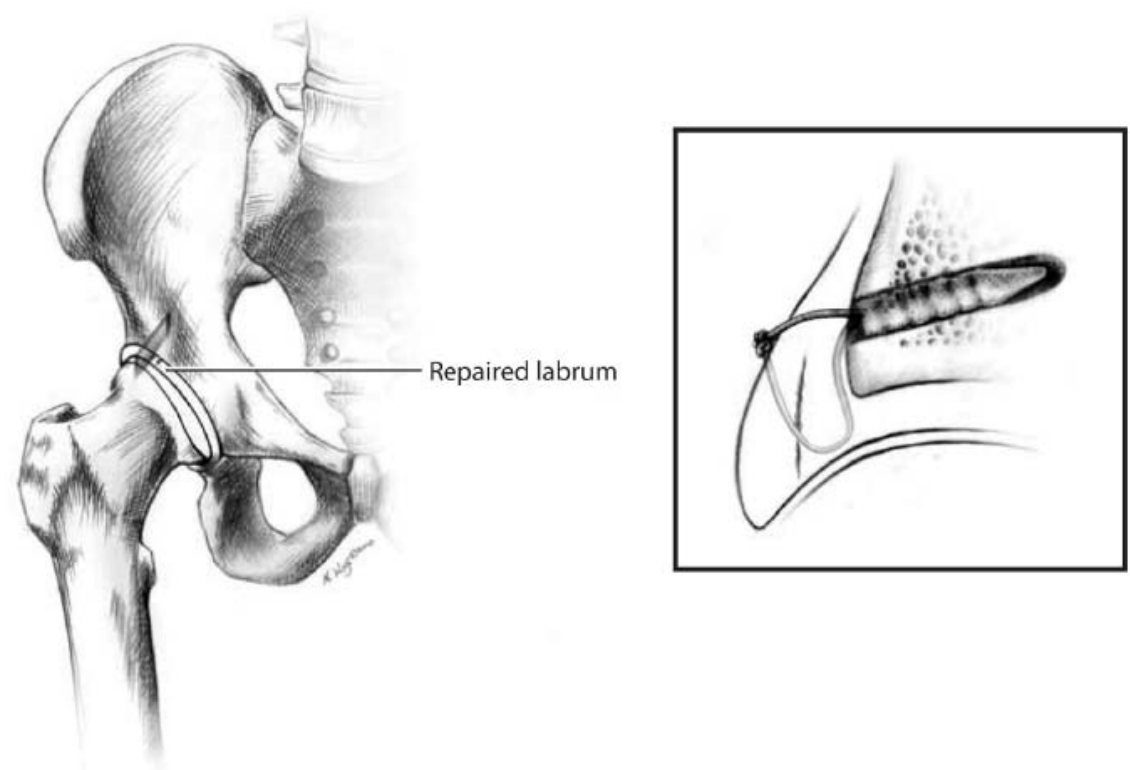

Fig. (16). Arthroscopic labral repair may involve single- or double-loaded anchors, with knots tied on the outer capsular surface away from the joint surface.

patients treated with labral debridement, Robertson et al., reported $67 \%$ of 58 patients and $91 \%$ of 22 patients were satisfied with their results at 3.5 years $[33,34]$.

\section{ARTHROSCOPY FOR FAI}

\section{Surgical Management of FAI}

Surgical management of a patient with labral tear and FAI involves addressing both the labrum - repair or debridement, as described above - and the underlying bony abnormality. If the FAI is not addressed surgically, the prob- lem may simply recur. Thus, the goals of surgical treatment for FAI include labral preservation and correction of any underlying abnormal bone morphology.

The arterial blood supply to the femoral head is through an anastomosis of a branch of the obturator artery in the ligamentum teres, and branches from the medial and lateral circumflex arteries from the deep femoral artery. The principal supply comes from the retinacular vessels from the medial femoral circumflex artery along the posterior inferior and posterior superior femoral neck [24]. The vessels arise

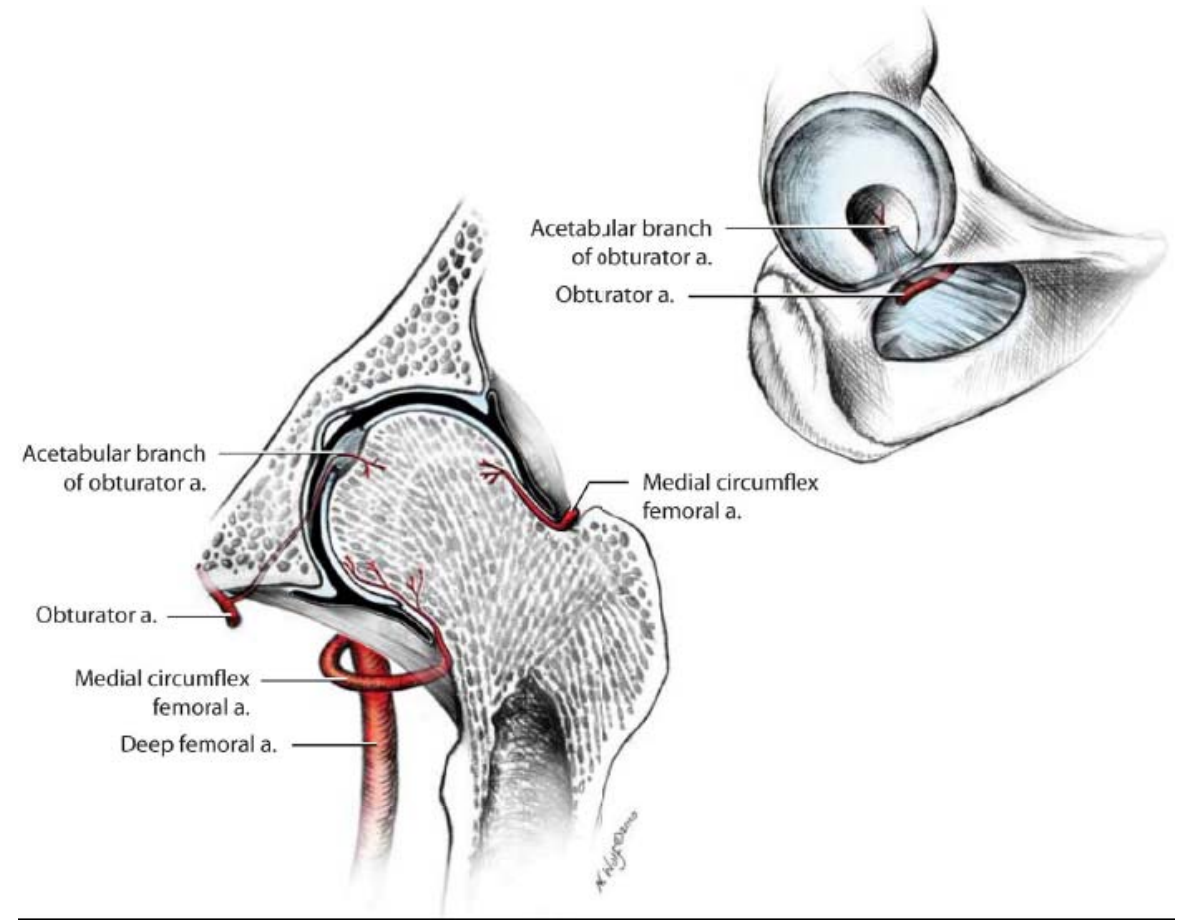

Fig. (17). During femoral neck osteoplasty, great care must be taken to avoid important blood vessels like the retinacular vessels from the medial femoral circumflex artery along the posterior inferior and posterior superior femoral neck. 


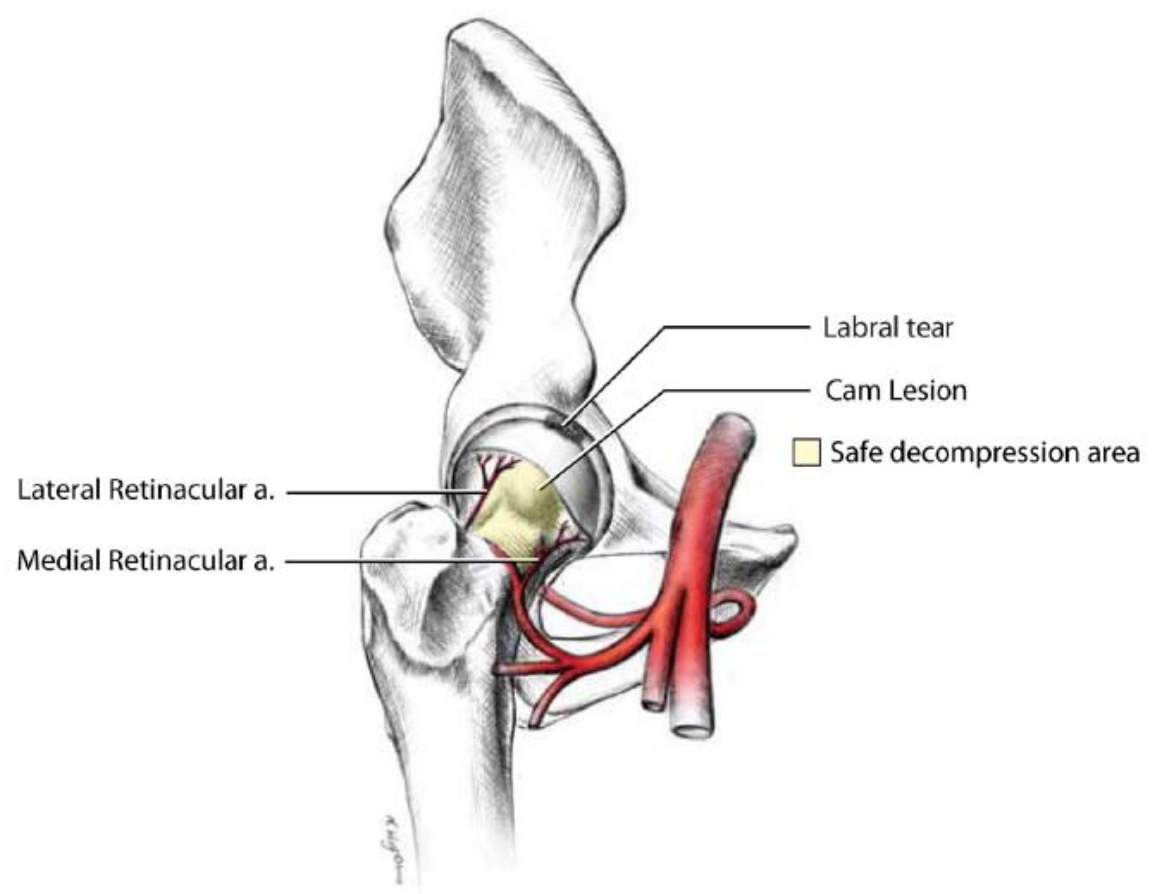

Fig. (18). In surgical correction of Cam impingement, it is important to avoid the retinacular vessels by staying in the safe decompression area.

within the lateral synovial retinaculum, which is a reflection of the capsule onto the neck of the femur (Fig. 17). During femoral neck osteoplasty, great care must be taken to avoid these vessels. Failure to do so can lead to avascular necrosis of the femoral head and joint collapse.

In restoration of the femoral head-neck contour to address Cam impingement, care must be taken during osteoplasty to stay proximally in the safe anterolateral and anterior regions, away from the retinacular vessels (Fig. 18). Mardones et al., have shown that resection of anything more than $30 \%$ the surface area of the femoral head-neck junction may be excessive and can lead to femoral neck fracture postoperatively [35]. In addition, over-resection of the femoral neck-head junction can lead to a loss of the labral seal during hip movement.

In the case of Pincer impingement, surgical treatment involves carefully trimming the excess acetabular bone away from the labrum using a high-speed burr, using fluoroscopy to guide the amount of resection. Fluoroscopic guidance is essential during acetabular rim trimming to prevent excessive resection of the acetabular rim, which can lead to instability of the hip. This technique preserves and recesses the labrum back to a normal anatomic acetabular rim without violating the chondrolabral junction (Fig. 19). The labrum is then reattached using bone anchors loaded with nonabsorbable sutures. Care must be taken not to trim any more acetabular bone than is necessary, as excessive overresection of the acetabular rim may lead to undercoverage of the femoral head and a resulting tendency for superolateral migration.

It is important to recognize that FAI is most often caused by a combination of acetabular and femoral head-neck impingement lesion. Both bony abnormalities must be addressed at surgery for the procedure to be successful [1].

\section{Results of Surgical Management of FAI}

Overall results of arthroscopic treatment for FAI show predictable functional improvement with good pain relief, equaling the results of open decompression with labral repair [36-45]. For the procedure to be successful, it is imperative to treat patients prior to the onset of significant joint space narrowing and degenerative changes. Labral preservation appears to improve the results and should be attempted in properly selected patients [31].

In a 2007 publication, Espinosa et al., reported the preliminary results for the treatment of FAI with labral reattachment. The authors found that patients who had reattachment of the labrum recovered earlier and had superior radiographic results when compared with patients who had resection of the labrum [33]. Other authors have reported similar results with arthroscopic treatment of FAI with concomitant labral repair $[31,40]$. In addition, a recent prospective study of the surgical treatment of FAI with chondrolabral dysfunction revealed good to excellent results in 112 patients when there was less than two millimeters of joint space narrowing. In the same study, patients who had labral repair did better than those with labral debridement [28]. Currently there are no randomized, prospective studies of young active patients with FAI and labral tears [30].

\section{SUMMARY}

Labral tear and FAI are increasingly recognized causes of hip and groin pain and disability. Clinicians should have a high index of suspicion for these problems, as early diagnosis and management may avert or attenuate the risk of subsequent osteoarthritis. Nonoperative management focuses on managing symptoms and optimizing strength and range of motion. Patients with persistent symptoms and functional limitations may consider surgical therapy. 


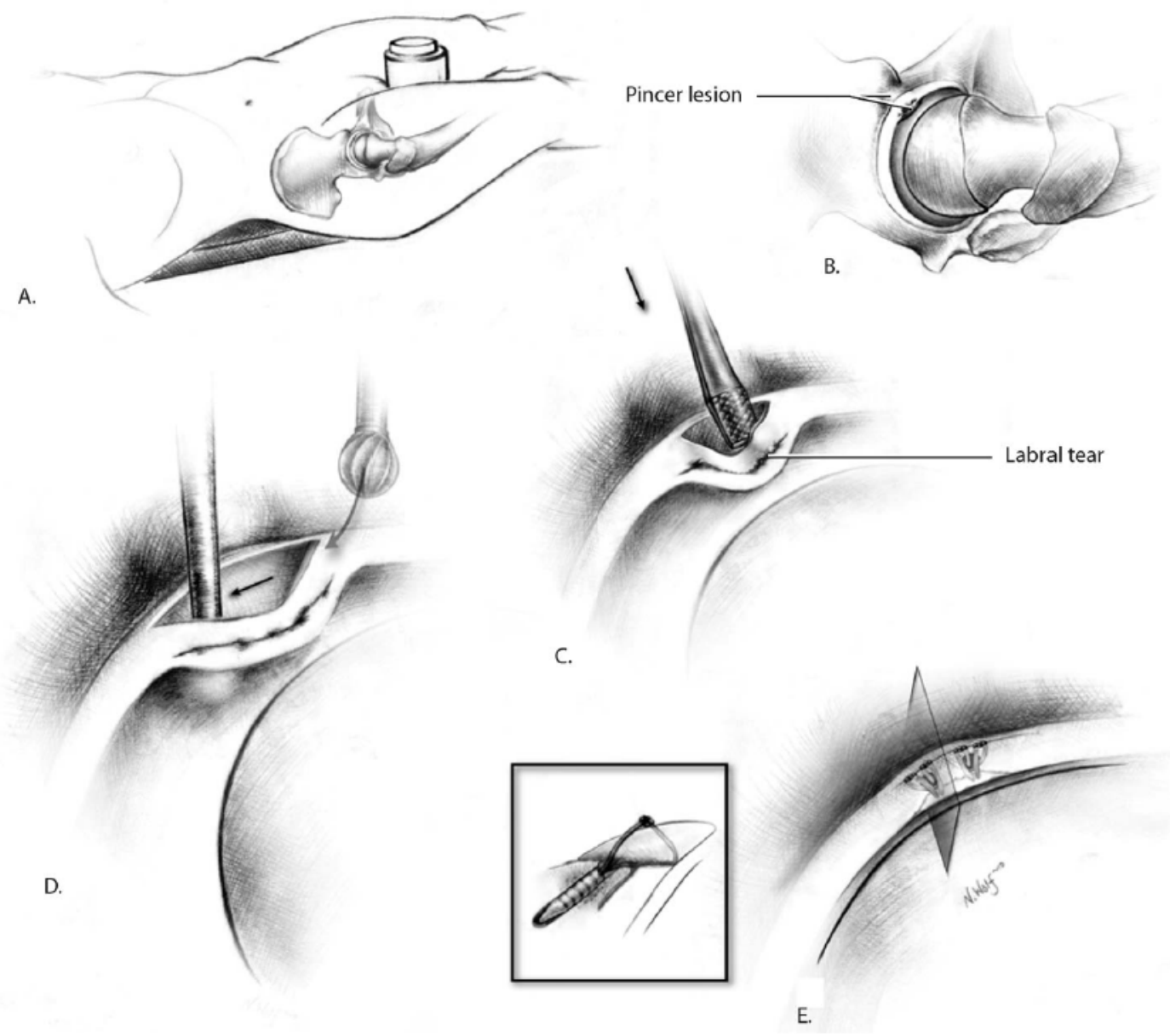

Fig. (19). Correcting Pincer impingement involves trimming the excess acetabular bone with a high-speed burr, while preserving the labrochondral junction and then reattaching the labrum using bone anchors loaded with non-absorbable sutures.

Surgery for labral tear and FAI can be done arthroscopically by surgeons with experience in these procedures. Hip arthroscopy has the ability to treat a variety of hip disorders and is now one of the most rapidly evolving orthopedic procedures in Sports Medicine. To be successful, the surgical techniques require an experienced hip arthroscopist and a detailed knowledge of the surgical anatomy of the hip. Results of current hip arthroscopy procedures equal those of open surgical procedures, though it should be noted that the evidence base for surgical approaches to labral tear and FAI consists largely of case series. Randomized controlled trials are needed to establish the efficacy of these surgical procedures in relieving pain and improving functional status. Long-term follow-up is needed to determine whether surgical approaches reduce the risk of osteoarthritis.

With improved diagnostic techniques and refined instrumentation designed specifically for the hip, the field will continue to advance. This anticipated growth in diagnostic and therapeutic approaches should be accompanied by welldesigned studies that determine which interventions actually improve relevant patient outcomes as hip arthroscopy becomes an increasingly common surgical technique for treating an ever-expanding list of conditions.

\section{COMPETING INTERESTS}

The authors have no competing interests to declare.

\section{ACKNOWLEDGEMENTS}

Many thanks to Nicole Wolf (http://www.nicolewolfart. $\mathrm{com} /$ ) for providing the illustrations used in this article and to Julian Prokopetz, BA, for expert editorial assistance.

\section{FUNDING SOURCES}

This study was funded by the National Institutes of Health (NIH Grants P60 AR 47782 and K24 AR 02123). The NIH played no role in writing or approving this article beyond providing the funding.

\section{REFERENCES}

[1] Crawford JR, Villar RN. Current concepts in the management of femoroacetabular impingement. J Bone Joint Surg Br 2005; 87: 1459-62.

[2] Byrd JW, Pappas JN, Pedley MJ. Hip arthroscopy: an anatomic study of portal placement and relationship to the extra-articular structures. Arthroscopy 1995; 11: 418-23.

[3] Dienst M, Godde S, Seil R, Hammer D, Kohn D. Hip arthroscopy without traction: In vivo anatomy of the peripheral hip joint cavity. Arthroscopy 2001; 17: 924-31.

[4] Santori N, Villar RN. Acetabular labral tears: result of arthroscopic partial limbectomy. Arthroscopy 2000; 16: 11-5.

[5] Konrath GA, Hamel AJ, Olson SA, Bay B, Sharkey NA. The role of the acetabular labrum and the transverse acetabular ligament in load transmission in the hip. J Bone Joint Surg Am 1998; 80: 17818.

[6] McCarthy JC, Noble PC, Schuck MR, Wright J, Lee J. The Otto E. Aufranc Award: the role of labral lesions to development of early degenerative hip disease. Clin Orthop Relat Res 2001: 25-37. 
[7] Crawford MJ, Dy CJ, Alexander JW, et al. The 2007 Frank Stinchfield Award. The biomechanics of the hip labrum and the stability of the hip. Clin Orthop Relat Res 2007; 465: 16-22.

[8] Tan V, Seldes RM, Katz MA, Freedhand AM, Klimkiewicz JJ, Fitzgerald RH Jr. Contribution of acetabular labrum to articulating surface area and femoral head coverage in adult hip joints: an anatomic study in cadavera. Am J Orthop (Belle Mead NJ) 2001; 30: 809-12.

[9] Seldes RM, Tan V, Hunt J, Katz M, Winiarsky R, Fitzgerald RH Jr. Anatomy, histologic features, and vascularity of the adult acetabular labrum. Clin Orthop Relat Res 2001; 417: 232-40.

[10] Kelly BT, Weiland DE, Schenker ML, Philippon MJ. Arthroscopic labral repair in the hip: surgical technique and review of the literature. Arthroscopy 2005; 21: 1496-504.

[11] Ganz R, Parvizi J, Beck M, Leunig M, Notzli H, Siebenrock KA. Femoroacetabular impingement: a cause for osteoarthritis of the hip. Clin Orthop Relat Res 2003: 417: 112-20.

[12] Beck M, Kalhor M, Leunig M, Ganz R. Hip morphology influences the pattern of damage to the acetabular cartilage: femoroacetabular impingement as a cause of early osteoarthritis of the hip. J Bone Joint Surg Br 2005; 87: 1012-8.

[13] Johnston TL, Schenker ML, Briggs KK, Philippon MJ. Relationship between offset angle alpha and hip chondral injury in femoroacetabular impingement. Arthroscopy 2008; 24: 669-75.

[14] Leunig M, Beck M, Woo A, Dora C, Kerboull M, Ganz R. Acetabular rim degeneration: a constant finding in the aged hip. Clin Orthop Relat Res 2003: 201-7.

[15] Pfirrmann CW, Duc SR, Zanetti M, Dora C, Hodler J. MR arthrography of acetabular cartilage delamination in femoroacetabular cam impingement. Radiology 2008; 249: 236-41.

[16] Tannast M, Goricki D, Beck M, Murphy SB, Siebenrock KA. Hip damage occurs at the zone of femoroacetabular impingement. Clin Orthop Relat Res 2008; 466: 273-80.

[17] Wagner S, Hofstetter W, Chiquet M, et al. Early osteoarthritic changes of human femoral head cartilage subsequent to femoroacetabular impingement. Osteoarthritis Cartilage 2003; 11: 508-18.

[18] Ito K, Minka MA 2nd, Leunig M, Werlen S, Ganz R. Femoroacetabular impingement and the cam-effect. A MRI-based quantitative anatomical study of the femoral head-neck offset. J Bone Joint Surg Br 2001; 83: 171-6.

[19] Kassarjian A, Yoon LS, Belzile E, Connolly SA, Millis MB, Palmer WE. Triad of MR arthrographic findings in patients with cam-type femoroacetabular impingement. Radiology 2005; 236: 588-92.

[20] Leunig M, Casillas MM, Hamlet M, et al. Slipped capital femoral epiphysis: early mechanical damage to the acetabular cartilage by a prominent femoral metaphysis. Acta Orthop Scand 2000; 71: 3705 .

[21] Notzli HP, Wyss TF, Stoecklin CH, Schmid MR, Treiber K, Hodler $\mathrm{J}$. The contour of the femoral head-neck junction as a predictor for the risk of anterior impingement. J Bone Joint Surg Br 2002; 84: 556-60.

[22] Siebenrock KA, Wahab KH, Werlen S, Kalhor M, Leunig M, Ganz R. Abnormal extension of the femoral head epiphysis as a cause of cam impingement. Clin Orthop Relat Res 2004: 54-60.

[23] Siebenrock KA, Schoeniger R, Ganz R. Anterior femoro-acetabular impingement due to acetabular retroversion. Treatment with periacetabular osteotomy. J Bone Joint Surg Am 2003; 85-A: 27886.

[24] Ganz R, Gill TJ, Gautier E, Ganz K, Krugel N, Berlemann U. Surgical dislocation of the adult hip a technique with full access to the femoral head and acetabulum without the risk of avascular necrosis. J Bone Joint Surg Br 2001; 83: 1119-24.
[25] Kelly BT, Williams RJ 3rd, Philippon MJ. Hip arthroscopy: current indications, treatment options, and management issues. Am J Sports Med 2003; 31: 1020-37.

[26] Mason JB. Acetabular labral tears in the athlete. Clin Sports Med 2001; 20: 779-90.

[27] Philippon MJ, Schenker ML. Arthroscopy for the treatment of femoroacetabular impingement in the athlete. Clin Sports Med 2006; 25: 299-308, ix.

[28] Philippon MJ, Briggs KK, Yen YM, Kuppersmith DA. Outcomes following hip arthroscopy for femoroacetabular impingement with associated chondrolabral dysfunction: minimum two-year followup. J Bone Joint Surg Br 2009; 91: 16-23.

[29] Sierra RJ, Trousdale RT, Ganz R, Leunig M. Hip disease in the young, active patient: evaluation and nonarthroplasty surgical options. J Am Acad Orthop Surg 2008; 16: 689-703.

[30] Bedi A, Chen N, Robertson W, Kelly BT. The management of labral tears and femoroacetabular impingement of the hip in the young, active patient. Arthroscopy 2008; 24: 1135-45.

[31] Philippon MJ, Schenker ML. A new method for acetabular rim trimming and labral repair. Clin Sports Med 2006; 25: 293-7, ix.

[32] Byrd JWT. Hip Arthroscopy, the supine approach: technique and anatomy of the intraarticular and peripheral compartments. Tech Orthop 2005; 20: 17-31.

[33] Espinosa N, Rothenfluh DA, Beck M, Ganz R, Leunig M. Treatment of femoro-acetabular impingement: preliminary results of labral refixation. J Bone Joint Surg Am 2006; 88: 925-35.

[34] Robertson WJ, Kadrmas WR, Kelly BT. Arthroscopic management of labral tears in the hip: a systematic review of the literature. Clin Orthop Relat Res 2007; 455: 88-92.

[35] Mardones RM, Gonzalez C, Chen Q, Zobitz M, Kaufman KR, Trousdale RT. Surgical treatment of femoroacetabular impingement: evaluation of the effect of the size of the resection. J Bone Joint Surg Am 2005; 87: 273-9.

[36] Bare AA, Guanche CA. Hip impingement: the role of arthroscopy. Orthopedics 2005; 28: 266-73.

[37] Beaule PE, Le Duff MJ, Zaragoza E. Quality of life following femoral head-neck osteochondroplasty for femoroacetabular impingement. J Bone Joint Surg Am 2007; 89: 773-9.

[38] Ilizaliturri VM Jr, Orozco-Rodriguez L, Acosta-Rodriguez E, Camacho-Galindo J. Arthroscopic treatment of cam-type femoroacetabular impingement: preliminary report at 2 years minimum follow-up. J Arthroplasty 2008; 23: 226-34.

[39] Khanduja V, Villar RN. The arthroscopic management of femoroacetabular impingement. Knee Surg Sports Traumatol Arthrosc 2007; 15: 1035-40.

[40] Larson CM, Giveans MR. Arthroscopic management of femoroacetabular impingement: early outcomes measures. Arthroscopy 2008; 24: 540-6.

[41] May O, Matar WY, Beaule PE. Treatment of failed arthroscopic acetabular labral debridement by femoral chondro-osteoplasty: a case series of five patients. J Bone Joint Surg Br 2007; 89: 595-8.

[42] Murphy S, Tannast M, Kim YJ, Buly R, Millis MB. Debridement of the adult hip for femoroacetabular impingement: indications and preliminary clinical results. Clin Orthop Relat Res 2004: 178-81.

[43] Philippon M, Schenker M, Briggs K, Kuppersmith D. Femoroacetabular impingement in 45 professional athletes: associated pathologies and return to sport following arthroscopic decompression. Knee Surg Sports Traumatol Arthrosc 2007; 15: 908-14.

[44] Philippon MJ, Stubbs AJ, Schenker ML, Maxwell RB, Ganz R, Leunig M. Arthroscopic management of femoroacetabular impingement: osteoplasty technique and literature review. Am J Sports Med 2007; 35: 1571-80.

[45] Shindle MK, Voos JE, Heyworth BE, et al. Hip arthroscopy in the athletic patient: current techniques and spectrum of disease. J Bone Joint Surg Am 2007; 89 (Suppl 3): 29-43.

(C) Martin and Katz; Licensee Bentham Open.

This is an open access article licensed under the terms of the Creative Commons Attribution Non-Commercial License (http://creativecommons.org/licenses/by-nc/3.0/) which permits unrestricted, non-commercial use, distribution and reproduction in any medium, provided the work is properly cited. 